\title{
HIGH POWER FAST KICKER SYSTEM FOR SNS BEAM EXTRACTION*
}

\author{
W. Zhang, J. Sandberg, N. Tsoupas, J. Mi, R. Lambiase, \\ R. Lockey, C. Pai, J. Tuozzolo, T. Nehring, and D. Warburton \\ Collider-Accelerator Department \\ Brookhaven National Laboratory \\ Upton, NY 11973, USA
}

Abstract

A Blumlein topology based high peak power, high repetition rate, and low beam impedance fast extraction kicker system for ORNL, Spallation Neutron Source (SNS) is being developed at Brookhaven National Laboratory. The large magnet window size, large deflecting angle, low beam impedance termination and fast deflecting field rise time demand a very strong pulsed power source to drive the SNS extraction fast kicker magnet. This system consists of fourteen high voltage modulators and fourteen lumped kicker magnet sections. All modulators will be located in a service building outside the beam tunnel, which is a revised design requirement adopted in the mid 2000 . The high current pulses generated by the high power modulators will be delivered through high voltage pulsed transmission cables to each kicker magnet sections. The designed output capacity of this system, is in multiple GVA. Its first article modulator has been constructed and is being tested. In this paper, we present the system overview, project status and the advantages of this new conceptual design.

\section{INTRODUCTION}

The Main Accumulator Ring of the Spallation Neutron Source (SNS) has chosen four-fold lattice symmetry. Each straight is dedicated to a particular function, such as, Injection, Extraction, RF, or Collimator. The layout of the lattice is shown in Figure 1. The Extraction Fast Kicker Magnet will be located in the upstream portion of the Extraction straight section followed by an extraction Septum Magnet and a beam gap kicker.

The main design goal of the extraction system is to extract beam vertically from the accumulator in a single turn, two-step fashion. At extraction, the beam bunch length is $645 \mathrm{nS}$, and a $250 \mathrm{nS}$ gap is reserved for the Extraction Fast Kicker deflection field rise time.

The extraction fast kicker has a total of fourteen magnet section, seven magnet sections will be located upstream of a vertical focusing, horizontal defocusing quadrupole doublet, and seven downstream from it. The deflection generated by the upstream kicker magnet sections will be weakened by the quadrupole doublet's vertical focusing magnetic field. The field of the second set of kicker magnet sections will add to the strength of the kicker deflection force. A few constrains on the design include:

1. The beam deflected by the upstream kicker sections shall not be spread on to the quad magnet;

2. The beam deflected by the kicker shall not be spread onto the septum magnet and the transport line components;

3. With one kicker module failure, upstream or downstream, the beam shall still be extracted out cleanly.

SNS is a fast cycling machine, which will be operated at $60 \mathrm{~Hz}$ repetition rate at beginning, and is expected to be upgraded to $120 \mathrm{~Hz}$ operations in the future. The radiation level might be high in the Extraction section. For the concerns of radiation safety, system serviceability, maintainability, and tunnel space, etc. a new design request was directed by the SNS Project Office to have all Extraction Fast Kicker Modulators relocated from inside ring tunnel to a new service building. A new conceptual design [1] was proposed in response to this request.

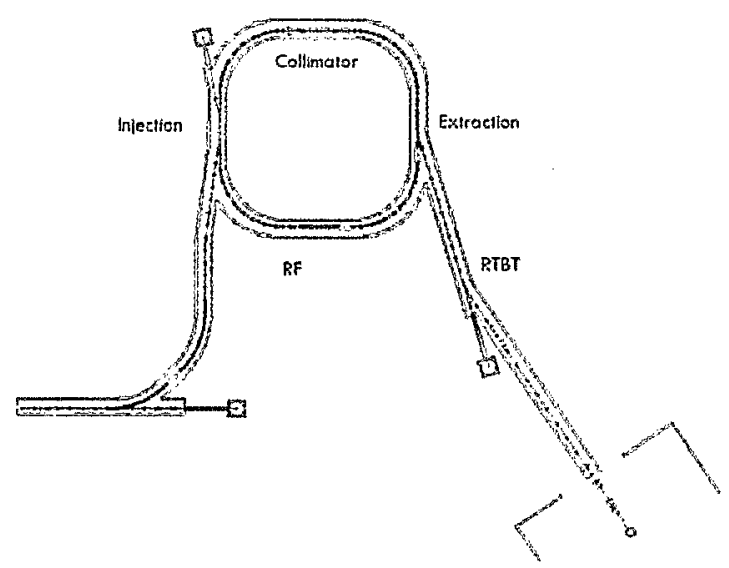

Figure 1. The SNS Accumulator Ring Lattice

\section{SYSTEM DESCRIPTION}

A large vertical deflection is required to extract beam from SNS accumulator. This demands a very high strength pulsed deflection field. In addition, a $25 \mathrm{ohm}$ parallel termination resistor was suggested by Accelerator

*Work performed under the auspices of the U.S. Department of Energy. 
System Review Committee (ASRC) to lower the beam impedance. And, it requires double the modulator current.

To catch up with the SNS Project schedule, complete the system within reasonable budget, and to satisfy all the technical requirements, we evaluated several possible design options. We choose the Blumlein modulator topology, as shown in Figure 2, for it gives the best technical solution to satisfy all of the requirements simultaneously.

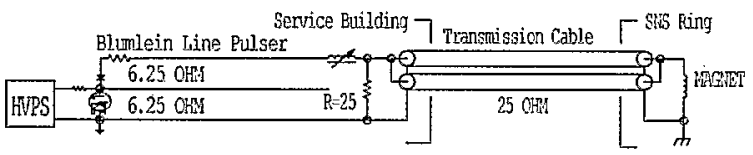

Figure 2. Simplified SNS Extraction Fast Kicker Circuit Diagram

This new design features:

1. The Blumlein Pulse Forming Network to lower the voltage during energy storage;

2. A $25 \mathrm{ohm}$ parallel resistor to lower beam impedance;

3. The full current reflection at magnet end to double the output;

4. The Hollow-Anode thyratron to handle reverse current;

5. The diode-resistor brunch to minimize reflection;

6. Two coaxial cables per each modulator for output pulse transmission,

It can be optimised with other system parameters, as presented in reference [1] and [2], to achieve higher design margin of the high voltage modulator, and enhanced its reliability. With different optimisation options, it is decided to benefit accelerator physics program. This system can accommodate beam acceptance of $480 \pi$-mm during beam accumulation, and $400 \pi-\mathrm{mm}$ during beam extraction. As a result, the current required to generate the same magnetic field and the voltage of the modulator have largely increased.

In Table 1, we list the most recent version of parameters and dimensions.

Table 1. Main Parameters of the SNS Extraction Fast Kicker System

\begin{tabular}{|l|l|}
\hline Beam Rigidity & $5.6575 \mathrm{~T}-\mathrm{M}$ \\
\hline Proton Momentum & $1.0 \mathrm{GeV}$ \\
\hline Extraction Type & Single-turn \\
\hline Magnet Window & Full aperture \\
\hline $\begin{array}{l}\text { Beam gap during } \\
\text { extraction }\end{array}$ & $250 \mathrm{nS}$ \\
\hline Maximum extraction rate & $60 \mathrm{~Hz}$ \\
\hline Pulse Flat-top length & $>645 \mathrm{nS}$ \\
\hline Pulse Flat-top tolerance & $+/-3 \%$ \\
\hline & \\
\hline Pulse rise time & $200 \mathrm{nS}(1 \%-95 \%)$ \\
\hline Pulse fall time & $<16.6 \mathrm{mS}$ \\
\hline Kicker strength & $\begin{array}{l}1.276 \text { to } 1.775 \text { mrad per } \\
\text { section }\end{array}$ \\
\hline
\end{tabular}

\begin{tabular}{|l|l|}
\hline $\begin{array}{l}\text { Kicker Horizontal } \\
\text { Aperture }\end{array}$ & $120 \mathrm{~mm}$ to $211.3 \mathrm{~mm}$ \\
\hline Kicker Vertical Aperture & $166 \mathrm{~mm}$ to $243 \mathrm{~mm}$ \\
\hline Kicker Length & $\begin{array}{l}390 \mathrm{~mm} \text { to } 505 \mathrm{~mm} \text { per } \\
\text { section }\end{array}$ \\
\hline Operating Voltage & $<35 \mathrm{kV}$ \\
\hline Operating Current & $<2.5 \mathrm{kA}$ \\
\hline
\end{tabular}

As a fast kicker system, this is one of the most powerful systems. It reaches to several GVA total output pulse capacity. The repetition rate is $60 \mathrm{~Hz}$, and the operation is continuous.

The maximum charging voltage of the Blumlein PFN is $50 \mathrm{kV}$, and the maximum switch current is $8 \mathrm{kA}$ each. The peak output current per module is $4 \mathrm{kA}$ driving through an inductive load magnet with a 200 ns rise time. It is designed for an output potential of $100 \mathrm{kV}$ under open load condition, and an output current of $4 \mathrm{kA}$ per module with matched load condition. A total of fourteen modulators and magnet sections are being designed and constructed. The overall system layout is shown in Figure 3.

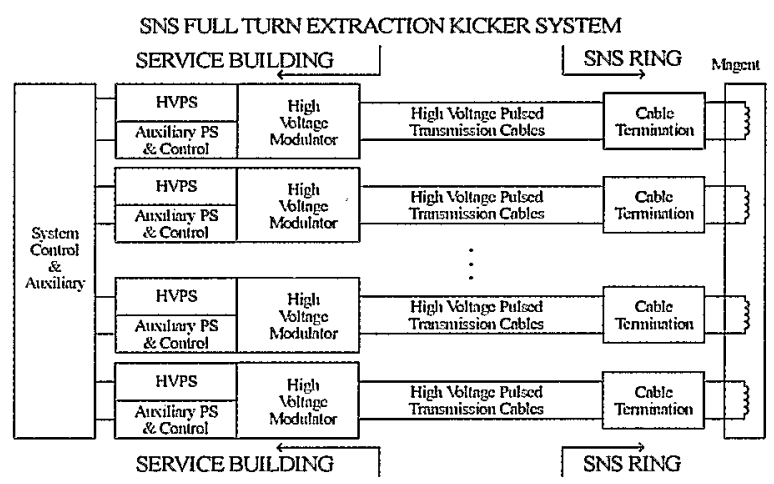

Figure 3. SNS Extraction Fast Kicker System Layout

To best comply with environmental concerns of the SNS, the DOW corning 561 Silicon fluid will be used as high voltage insulation media and cooling agent. It was chosen for its environmental friendliness and excellent high voltage property. A suggestion to use biodegradable insulation fluid, such as Envirotemp ${ }^{\circledR}$ FR3 $^{\mathrm{TM}}$ Natural Ester-based Transformer Fluid, was received. We conducted an investigation on this issue with capacitor vendors as well as power engineers. The Envirotemp ${ }^{\text {(3) }}$ FR3 ${ }^{\mathrm{TM}}$ has a much higher Kinematic Viscosity at lower temperature, especially high at 7-day hold rating. This fluid has not been used in high voltage pulsed capacitors, and the future service building at SNS might not be temperature regulated. Therefore, the silicon fluid seems to be a better agent. The same silicon fluid will be used in the liquid filled pulse capacitors.

A prototype high voltage fluid tank has been designed and built at Brookhaven National Laboratory. The high 
voltage modulator core section includes entire high voltage Blumlein Pulse Forming Network, switching thyratron assembly, reversing diode stack, resistor stack, grounding relay, etc. It is electrically isolated from the fluid tank enclosure, and can be lifted out from the fluid tank for in air testing and service. Figure 4 and Figure 5 show the modulator inside portion.

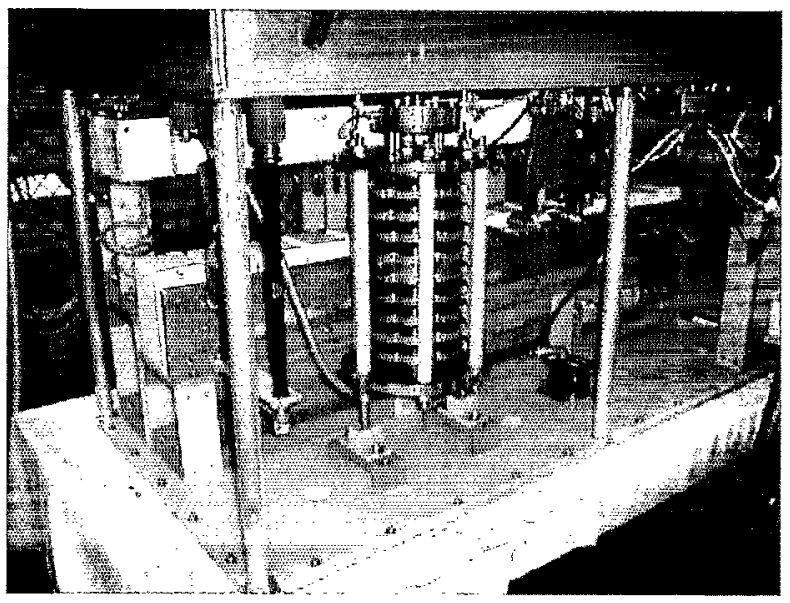

Figure 4. High Voltage Portion of the SNS Extraction Fast Kicker Modulator

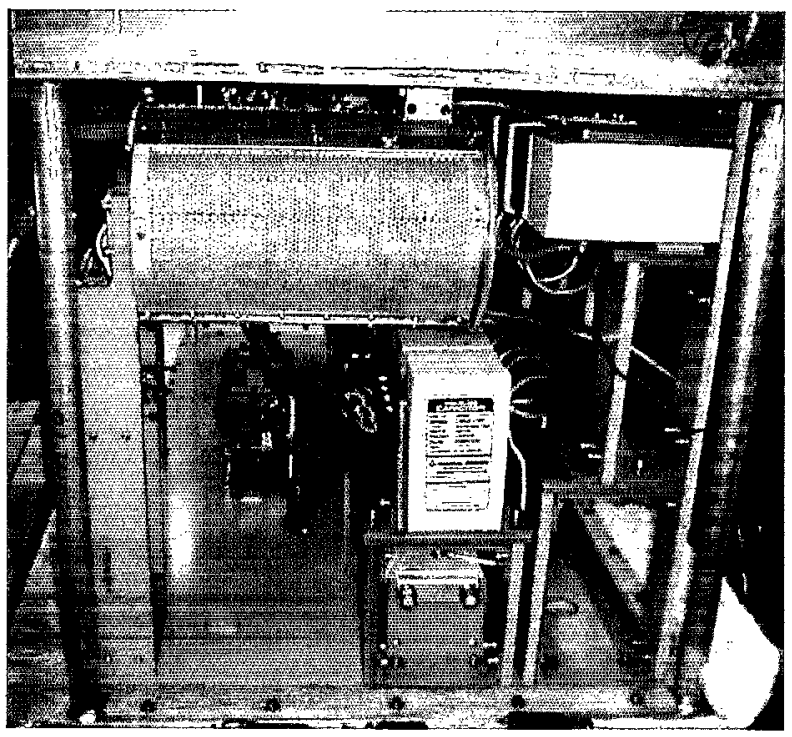

Figure 5. High Voltage Portion of the SNS Extraction Fast Kicker Modulator - Side View

Critical components used in this design are based on available commercial products. The switching device is a CX1925X Hollow Anode Thyratron by the Marconi Applied technology. The thyratron has an excellent switching speed, which helps to ensure a fast pulse rise time of the load current. And, the ultra low inductance, 15 $\mathrm{nH}$, silicon fluid filled high energy pulsed capacitor for use in the Pulse Forming Network is developed by
General Atomics Energy Products. Twelve $6 \mathrm{kV}$ rated fast recovery diode, by Eupec, are used in each of the reversing diode stack. The output high voltage pulse cable is designed by Times Microwave System. A set of ferrite rings is used as saturable inductors to provide high impedance isolation between Blumlein PFN and the output cable with the termination resistor during beam accumulation. The ferrite will saturate and change to a very low inductance during output current rising to suppress the dark current.

\section{MODEL AND PRO'TOTYPE TESTS}

Several steps were taken to ensure the feasibility and achievability of the design. One of the major concerns was that the pulse flattop ripple might exceed requirement due to series inductance of the PFN capacitor. Our estimation is that the PFN inductor coil will couple to its adjacent ones, and the coupling inductance is in the order of $20 \mathrm{nH}$. Theoretically, the coupling inductance shall cancel the series inductance of PFN capacitor by the same amount. Hence, we required that the inductance of the PFN capacitor to be less than $20 \mathrm{nH}$. A proof-of-principle circuit was build and tested up to a few kilo-volts, reached to about $14.5 \%$ of the required current level [1]. The result is very satisfactory. While waiting for the prototype high voltage modulator to be designed and assembled, we build a model circuit with Blumlein PFN using actual GA low inductance capacitor, a small thyratron, and tested with the prototype magnet in its vacuum chamber. It achieved all critical pulse parameter specifications at $10 \mathrm{kV}$ charging voltage level. A current waveform of the model circuit was shown in Figure 6. It has an excellent agreement with computer-simulated waveform, as shown in Figure 7.

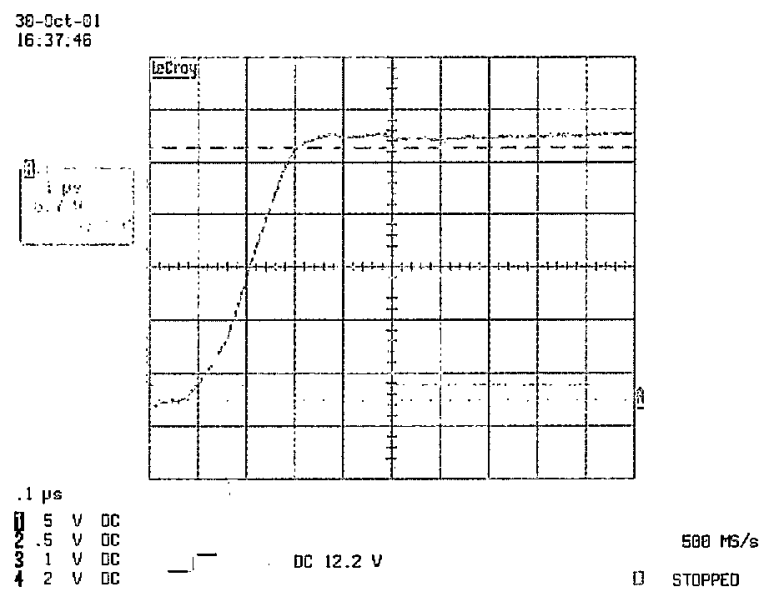

Figure 6. The Current Waveform of the Model Circuit 


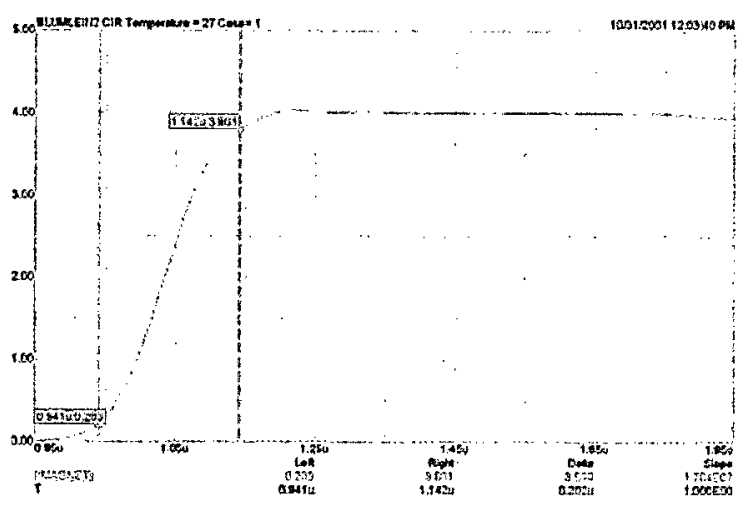

Figure 7. Simulated Output Current Waveform

A comparison was made with PFN using ceramic capacitor and fluid filled capacitor. The results show no difference in current waveform. However, a slight difference was observed with using small or large thyratrons.

The prototype modulator has been tested up to $40 \mathrm{kV}$ in air for waveform verification. As shown in Figure 8, it has a rise time of $200 \mathrm{~ns}$ from $2 \%$ to $99 \%$ or 0 to $95 \%$. The pulse flattop ripple is $\pm 1.17 \%$ of the pulse amplitude. Its pulse flattop duration is about $800 \mathrm{nS}$. The load current amplitude reaches to 2744 ampere.

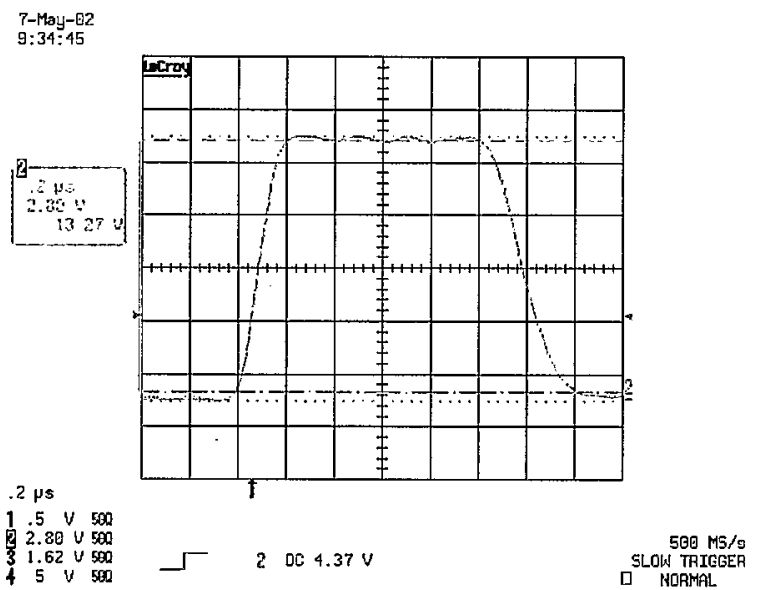

Figure 8. The Load Current Waveform of the SNS Extraction Fast Kicker at $40 \mathrm{kV}$

The pulse flattop ripple and the rise time have some dependency on the PFN tuning, switching speed, size of the saturable inductor, and current level. At $35 \mathrm{kV}$ in air, the flattop ripple is about $\pm 1.6 \%$, as shown in Figure 9 .

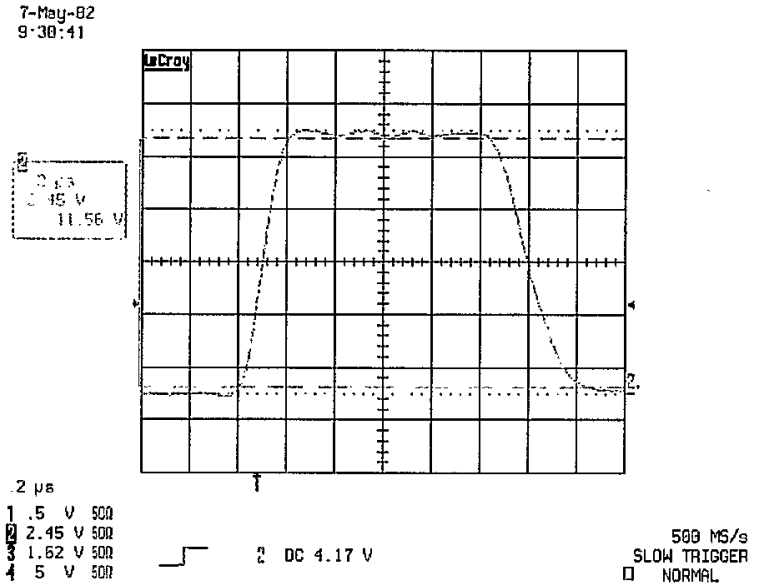

Figure 9. The Load Current Waveform of the SNS Extraction Fast Kicker at $35 \mathrm{kV}$

The prototype modulator has been tested with silicon liquid for power and lifetime check for 200 hours at 35 $\mathrm{kV}$ and $60 \mathrm{~Hz}$ repetition rate, and 8 hours at $40 \mathrm{kV}$. Additional lifetime test will be conducted for verification of the design and system reliability.

\section{ACKNOLEGMENTS}

We would like to express our appreciation to the R. Zapasek, J. Addessi, K. Hartmann, and S. Perlstein for their excellent technical support.

\section{REFERENCE}

[1]. W. Zhang, et al., "A New Conceptual Design of the SNS Full Turn Fast Extraction Kicker Power Supply System", 2001 Particle Accelerator Conference, June 2001, pp. 3714-3716.

[2].W. Zhang, et al., "SNS full Turn Fast Extraction Kicker System", BNL Internal Technical Proposal Presentation, July, 2000. 